\title{
Effects of Supplemental Light Source on Basil, Dill, and Parsley Growth, Morphology, Aroma, and Flavor
}

\author{
Alexander G. Litvin and Christopher J. Currey \\ Department of Horticulture, 2206 Osborn Drive, Iowa State University, Ames, IA 50011 \\ Lester A. Wilson \\ Department of Food Science and Human Nutrition, 536 Farm House Lane, Iowa State University, \\ Ames, IA 50011
}

\begin{abstract}
AdDitional InDEX wORDs. culinary herbs, light-emitting diodes, greenhouse, controlled environment
AbSTRACT. Broad-spectrum high-pressure sodium (HPS) lamps are the standard for greenhouse supplemental lighting. However, narrow-spectra light-emitting diodes (LEDs) offer potential benefits for enhancing growth, photosynthesis $\left(P_{n}\right)$, and secondary metabolites in culinary herbs. Our objective was to quantify the effect of supplemental light source and spectra on growth, gas exchange, aroma, and flavor of culinary herbs. Basil (Ocimum basilicum 'Nufar'), dill (Anethum graveolens 'Fernleaf'), and parsley (Petroselinum crispum 'Giant of Italy') were transplanted into hydroponic systems in a glass-glazed greenhouse. Plants were provided with a supplemental photosynthetic photon flux $(P P F)$ density of $100 \mu \mathrm{mol} \cdot \mathrm{m}^{-2} \cdot \mathrm{s}^{-1}$ from an HPS lamp or LEDs with a low blue (B) to red (R) light ratio of 7:93 [low blue (LB)] or high B:R at 30:70 [high blue (HB)]. Compared with plants grown under HPS lamps, basil grown under LB and HB LED lighting was shorter, while only HB-grown parsley was shorter; height of dill was unaffected by light source. Basil and parsley shoot fresh weight was lower for HB-treated plants compared with HPS, though dill was unaffected by supplemental light source. Shoot dry mass of basil, dill, and parsley was unaffected by light source. Both LED treatments increased $\boldsymbol{P}_{\boldsymbol{n}}$ for basil and parsley compared with HPS-grown plants. Stomatal conductance $\left(g_{S}\right)$ was higher under LB and HB for basil compared with HPS in the morning and evening, but only HB-treated parsley was higher than HPS lighting in morning. Basil grown under LB, and parsley under both LEDs had lower chlorophyll fluorescence than those under HPS by the evening, but all three species had more chlorophyll b under LB light than HPS. Essential oil and phenolic accumulation were influenced by supplemental light treatment and responses varied among species. Lighting from LEDs resulted in a 2-fold increase in orientin and myristicin for basil and dill, respectively, while HB increased dillapiole concentration by $89 \%$ compared with HPS-grown dill. Notably, quercetin concentration was 2.8 times higher in dill grown under HB compared with HPS. Myrcene increased in all three species under either one (basil HB; dill LB) or both (parsley) LED lights compared with HPS. The increased content of aromatic and flavor compounds demonstrates the potential of supplemental lighting systems using specific wavelengths to add value; but the use of supplemental lighting requires an understanding of the additional stress on the photosynthetic mechanisms and the subsequent effect on biomass accumulation.
\end{abstract}

Culinary herbs are used globally as ingredients in cuisine and as therapeutic components in medications [Cook and Samman, 1996; U.S. Department of Agriculture (USDA), 2011]. Herbs such as basil (Ocimum basilicum), dill (Anethum graveolens), and parsley (Petroselinum crispum) are popular for their aroma and flavor attributes, nutritional value (Brown, 1991), historic cultural value (Cook and Samman, 1996; Justesen and Knuthsen, 2001), and ornamental appeal (Morales and Simon, 1996). Growing culinary herbs in controlled

Received for publication 20 May 2019. Accepted for publication 24 Sept. 2019. Published online 19 December 2019.

We gratefully acknowledge Peter Lawlor for greenhouse assistance, Erica Schlichte for data collecting and greenhouse assistance, JR Peters for fertilizer, and Smithers-Oasis Company for substrate.

The use of trade names in this publication does not imply endorsement by Iowa State University of products named nor criticism of similar ones not mentioned. A.G.L. is a Graduate Research Assistant.

C.J.C. is an Associate Professor.

L.A.W. is a University Professor.

C.J.C. is the corresponding author. E-mail: ccurrey@iastate.edu.

This is an open access article distributed under the CC BY-NC-ND license (https://creativecommons.org/licenses/by-nc-nd/4.0/). environment agriculture (CEA) facilities can enhance yield and quality of herbs through appropriate cultivar and production system selection (Walters and Currey, 2015) and managing mineral nutrition (De Pascale et al., 2006), air temperature (Chang et al., 2005), and light intensity and duration (Beaman et al., 2009; Chang et al., 2008).

Traditionally, broad-spectrum lamps such as HPS or metal halide have been used for supplemental greenhouse lighting, but inefficiencies increase thermal radiation and operating costs (Trouwborst et al., 2010) and prevent the close proximity of lamps to plants (Gomez et al., 2013). Modern high-intensity LED lighting provides narrow-spectra light including blue (B), red (R), and far-red (FR) wavelengths, among others, and offers new efficiencies in supplemental and sole-source lighting (Massa et al., 2008; Randall and Lopez, 2015). For example, the dry mass accumulated per unit of electrical use (grams per kilowatt hour) from LEDs have been reported to be as much as 4.7 times that of cool fluorescent lighting for dry mass of basil (Piovene et al., 2015), and intracanopy LEDs providing up to 4 times the fresh weight in grams per kilowatt hour of tomato (Solanum lycopersicum $\times S$. habrochaites) than under HPS. 
However, Hernández and Kubota (2015) reported cucumber (Cucumis sativus) grown under supplemental lighting had 3.0 and $3.3 \mathrm{~g} \cdot \mathrm{kWh}^{-1}$ under B and R LEDs, respectively, compared with $3.5 \mathrm{~g} \cdot \mathrm{kWh}^{-1}$ under HPS lighting. They noted higher efficiency LED lamps were currently on the market and could achieve up to $4 \mathrm{~g} \cdot \mathrm{kWh}^{-1}$.

Specific wavelengths of light common in LEDs, such as B and $\mathrm{R}$, play unique roles in plant responses. For example, $\mathrm{R}$ light contributes to biomass accumulation (Hernández and Kubota, 2012). Additionally, R light increases phenolic concentrations in plants compared with white light, but not to the same magnitude as B light (Li and Kubota, 2009). Blue light plays a central role in initial stomatal opening in the morning (Baroli et al., 2008; Wu et al., 2007), control of plant height (Hernández and Kubota, 2012), and promotion of photoprotective pigmentation (Taulavuori et al., 2016). Although B light can stimulate phenolic biosynthesis through the phenylpropanoid pathway (Taulavuori et al., 2016), increases are not linear as B light increases (Craver et al., 2017). Taken together, the use of B light for supplemental lighting should be carefully considered in controlled environments to balance morphological and physiological responses.

Some secondary metabolites, essential oils, and phenolic compounds comprising many of the aromas and flavors in culinary herbs are specifically promoted through light stress and increase with the quantity or duration of ultraviolet or B light (Blande et al., 2014; Dixon and Paiva, 1995; Kopsell et al., 2015; Taulavuori et al., 2016). These metabolites are dietary nutrients for human health (Cook and Samman, 1996; U.S. Department of Agriculture, 2011), promoting a range of benefits including controlling blood pressure and cholesterol, and reducing the risk for certain cancers (Huang et al., 2009; Pandey and Rizvi, 2009). Essential oils are considered beneficial to human health (Cook and Samman, 1996); and while high concentrations of certain oils like linalool can cause skin irritation (Prashar et al., 2004), toxic levels are only possible in concentrations much higher than conventionally produced by plants (Loughrin and Kasperbauer, 2003). It is thus possible to promote these signaling pathways through targeted supplemental lighting with specific spectra such as with ultraviolet or B light. While some research has been conducted on the growth (Fraszczak et al., 2014) and essential oil accumulation (Chang et al., 2008; Fernandes et al., 2013; Hammock, 2018) for basil, there is currently little to no literature comprehensively quantifying the effects of LED light quality compared with HPS lighting for both the growth and physiological responses in gas exchange and $P_{n}$ as support for aroma and flavor accumulation. Furthermore, even less literature exists on light quality effects for any combination of these parameters for either parsley or dill.

Although traditional light sources such as HPS are widely used supplemental sources, the targeted effect of narrowspectra LEDs offer new potential for enhancing growth, aroma, and flavor. Because of the role of light quality on $P_{n}$ and the isoprenoid and phenlypropanoid pathways for secondary metabolites such as essential oils and flavonoids, our objective was to quantify the effect of supplemental light source and spectra on growth, gas exchange, and aroma and flavor of culinary herbs grown hydroponically in a greenhouse. We hypothesized that the narrow-spectra LEDs will increase photochemical quenching, growth, and phenolic accumulation as compared with HPS lighting. Under equal light intensity, lighting with greater proportions of B light will increase aromatic and flavor compounds, although more compact, as compared with HPS lighting. Additionally, LEDs with a lower proportion of B light will be more photosynthetically efficient while increasing aromatic and flavor compounds in comparison with HPS lighting, with minimal yield penalty.

\section{Materials and Methods}

Plant materials and propagation. Seeds of basil (cv. Nufar), dill (cv. Fernleaf), and parsley (cv. Giant of Italy) supplied by a commercial seed company (Johnny's Selected Seeds, Winslow, ME) were sown (two seeds per cell) into 276cell phenolic foam propagation cubes (Oasis Horticubes XL; Smithers-Oasis, Kent, OH) initially saturated with deionized water and allowed to drain, placed in an environmental growth chamber (E-41; Percival Scientific, Perry, IA), and irrigated once with deionized water. During seed germination and seedling growth, air average daily temperature was $23 \pm$ $1.3{ }^{\circ} \mathrm{C}$ with a $24-\mathrm{h}$ set point of $23{ }^{\circ} \mathrm{C}$. A combination of fluorescent (Philips F25T8/TL741/Alto 25 W; Signify Holding, Eindhoven, The Netherlands) and incandescent lights (A15 FR 130V 3M 25W; Halco Lighting Technologies, Norcross, GA) provided $443 \pm 17 \mu \mathrm{mol} \cdot \mathrm{m}^{-2} \cdot \mathrm{s}^{-1}$ from 0600 to $2200 \mathrm{HR}$ throughout propagation. Light was measured with a quantum light sensor (SQ-222; Apogee Instruments, Logan, UT), and air temperature with a thermocouple (TMC1-HD; Onset Computer Corp., Bourne, MA), in a naturally aspirated solar shield (RS3; Onset) every $15 \mathrm{~s}$ in a growth chamber; and averages were recorded by a data logger (HOBO U12 PPFD/Temp, Onset Computer Corp.) every $15 \mathrm{~min}$. Seedlings were irrigated daily with deionized water supplemented with $100 \mathrm{mg} \cdot \mathrm{L}^{-1} \mathrm{~N}$ supplied from $16 \mathrm{~N}-1.8 \mathrm{P}-14.3 \mathrm{~K}$ water-soluble fertilizer (Jack's Hydro FeED; JR Peters, Allentown, PA). Seedlings were grown for 2 weeks (basil) or 3 weeks (parsley and dill) after sowing, before transplanting to the greenhouse.

Hydroponic CUlture AND GREenHOUSE ENVIRONMENT. Each cube was thinned to a single seedling per cell and individually transplanted into one of nine deep-flow technique (DFT) hydroponic units. Nutrient solution was contained by a plastic open tank measuring $15 \times 91 \times 182 \mathrm{~cm}$ (height $\times$ width $\times$ length), with a 227-L capacity (Active Aqua; Hydrofarm, Petaluma, CA). Initial nutrient solutions were comprised of deionized water supplemented with $53 \mathrm{mg}$ of $\mathrm{MgSO}_{4}$ and brought to an electrical conductivity (EC) of $1.5 \mathrm{dS} \cdot \mathrm{m}^{-1}$ by 16N-1.8P-14.3K water-soluble fertilizer (Jack's Hydro FeED). Twenty four plants of each species were placed into $5-\mathrm{cm}$ diameter black net pots (FarmTek, Dyersville, IA) inserted into 3.5-cm-diameter holes spaced $15 \mathrm{~cm}$ apart on an extruded polystyrene foam raft (Scoreboard; Dow, Midland, MI) placed directly on the nutrient solution such that the foam cubes were in direct contact with nutrient solution. Solution was aerated through six 15-cm-long air stones (Active Aqua) in each DFT system by a $110-\mathrm{L}$ air pump (Active Aqua). Another pump (Aqua 30-W, Active Aqua) circulated water through water heater/chillers (SeaChill TR-10; TECO, Terrell, TX) to maintain the nutrient solution at $22.5^{\circ} \mathrm{C}$. Nutrient solutions of each DFT system were monitored daily with a $\mathrm{pH} / \mathrm{EC}$ meter (HI 9813-6; Hanna Instruments, Woonsocket, RI) and adjusted using phosphoric and citric acid ( $\mathrm{pH}$ Down; General Hydroponics, Sebastopol, CA) or potassium bicarbonate (JR Peters) to maintain a target $\mathrm{pH}$ of 6.0 , while $\mathrm{EC}$ was maintained at 1.5 
$\mathrm{dS} \cdot \mathrm{m}^{-1}$ using a concentrated stock solution of $16 \mathrm{~N}-1.8 \mathrm{P}-14.3 \mathrm{~K}$ water-soluble fertilizer (Jack's Hydro FeED).

All systems were placed in a glass-glazed greenhouse located in Ames, IA (lat. $42^{\circ} \mathrm{N}$ ). Day and night temperature set points were 24 and $20^{\circ} \mathrm{C}$, respectively; the temperatures were maintained with radiant hot-water heating and fog cooling, and they were controlled using an environment computer controller (Titan; ARGUS Control Systems, Surrey, BC, Canada). Automated greenhouse controls (Titan; ARGUS Control Systems) provided adjustable shading using an aluminized shadecloth with $41 \%$ diffused light transmission (XLS 15 Revolux; Ludvig Svensson, Kinna, Sweden) on motorized rollers, resulting in a mean daily photosynthetic photon flux density $(P P F D)$ of $8.3 \pm 2.1 \mathrm{~mol} \cdot \mathrm{m}^{-2} \cdot \mathrm{d}^{-1}$.

SuPPlemental Lighting TREATMENTS. Ambient greenhouse PPFD was supplemented with $100 \mu \mathrm{mol} \cdot \mathrm{m}^{-2} \cdot \mathrm{s}^{-1}$ by lighting treatments between 0600 and 2200 HR. Each DFT system was placed underneath a 400-W HPS lamp (PL 3000; P.L. Light Systems, Beamsville, ON, Canada), or LEDs with low B:R (B-450 nm peak $\lambda$; R-670 nm peak $\lambda$ ) light ratio of 7:93 [LB (DR/B-low blue, Philips GreenPower LED Toplighting; Signify Holding)] or high B:R at 30:70 [HB (DR/B - high blue, Philips GreenPower LED Toplighting, Signify Holding] (Fig. 1). Mapping of light distribution across the growing area was done by recording light intensity every $10 \mathrm{~cm}$ across the surface of the raft using a spectroradiometer (PS-100, Apogee Instruments), adjusting lamp height, and wrapping lights with aluminum screening until the PPFD across treatment areas reached $102 \pm 2 \mu \mathrm{mol} \cdot \mathrm{m}^{-2} \cdot \mathrm{s}^{-1}$. Individual light treatments were isolated from one another by a 6-mm-thick black and white plastic sheeting (Hydrofarm) folded over to create partitions extending from above the lamp height to below the growing media.

Thermistors (CS215; Campbell Scientific, Logan, UT), inside an aspirated radiation shield (TS100, Apogee Instruments), and quantum sensors (LI-190R; LI-COR Biosciences, Lincoln, NE), placed in the middle of each DFT system, were connected to a data logger (CR1000, Campbell Scientific). These measured temperature and $P P F D$, respectively, every 30 s. Data were averaged and recorded by the data logger hourly, with daily averages calculated and logged.

Plant growth data collection and Calculation. Photosynthesis $\left(P_{n}\right), g_{\mathrm{S}}$, and transpiration $(E)$ were sampled and averaged from two plants within each repetition. Measurements were on fully expanded leaves about three nodes below the apical meristem by an infrared gas analyzer (LX-6400XT, LI-COR Biosciences) with a $6-\mathrm{cm}^{2}$ clear leaf chamber $20 \mathrm{~d}$ (basil) or $27 \mathrm{~d}$ (dill and parsley) after transplanting seedlings into hydroponic systems and initiating light treatments. Reference $\mathrm{CO}_{2}$ concentration in the gas analyzer chamber was $500 \mu \mathrm{mol} \cdot \mathrm{mol}^{-1}$ and water vapor was maintained at 8 mmol. Leaf chamber temperature was aspirated to greenhouse ambient conditions as previously described. Chlorophyll fluorescence $\left(F_{v} / F_{m}\right)$ was measured on the same leaves sampled for gas exchange using a portable fluorometer (Handy PEA; Hansatech, Pentney, Norfolk, UK) for darkadapted measurements. Leaves were dark adapted by placing a clip with a shutter (Hansatech) for $15 \mathrm{~min}$ before securing the flurometer to the clip and opening the shutter. Flurometer measurements were done by exciting tissue for one second with increasing light up to $3512 \mu \mathrm{mol} \cdot \mathrm{m}^{-2} \cdot \mathrm{s}^{-1}$ to saturate photosystem II, and data were expressed by $F_{v} / F_{m}$. To

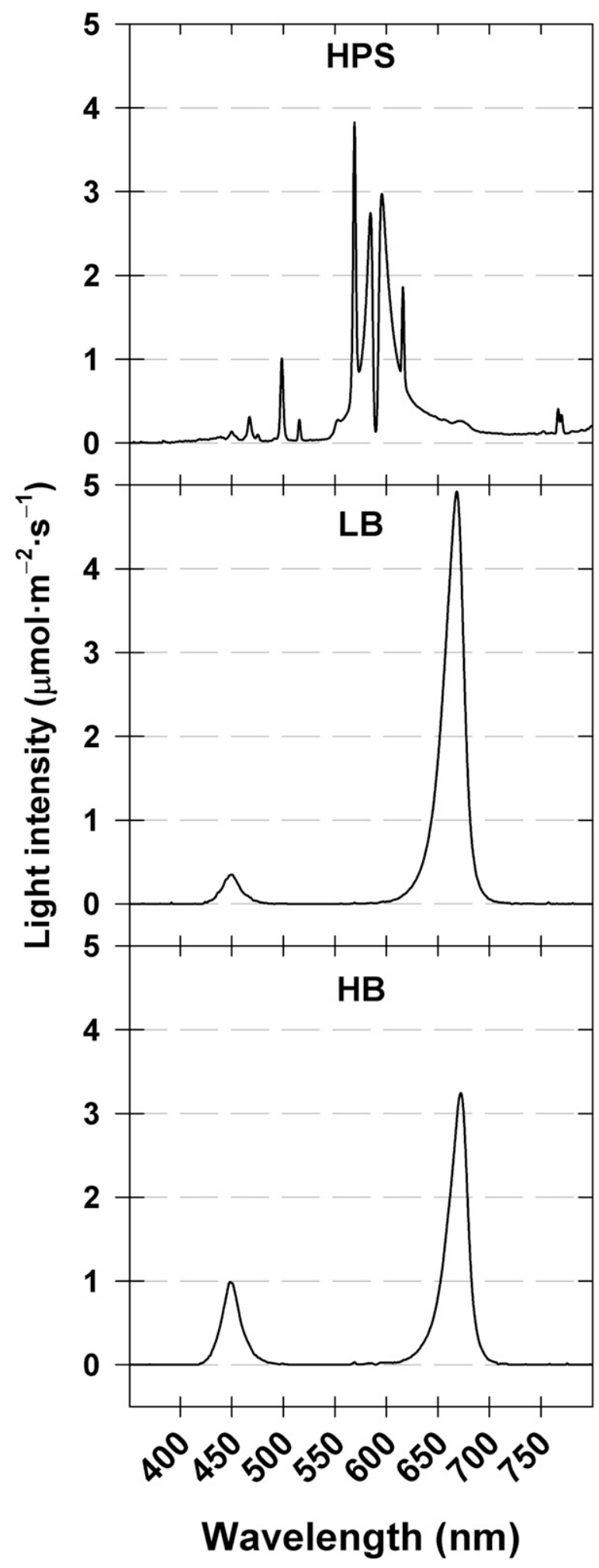

Fig. 1. Light spectra of supplemental light provided from high-pressure sodium (HPS) lamps or light-emitting diodes with a low blue (B) to red (R) ratio [LB (7:93 B:R)], or high B:R ratio [HB (30:70 B:R)].

measure the effect of daylength across photoperiod on treatments, gas exchange and $F_{v} / F_{m}$ were measured in the morning (between 0600 and $0800 \mathrm{HR}$ ), and in the evening (between 2000 and $2200 \mathrm{HR}$ ). 


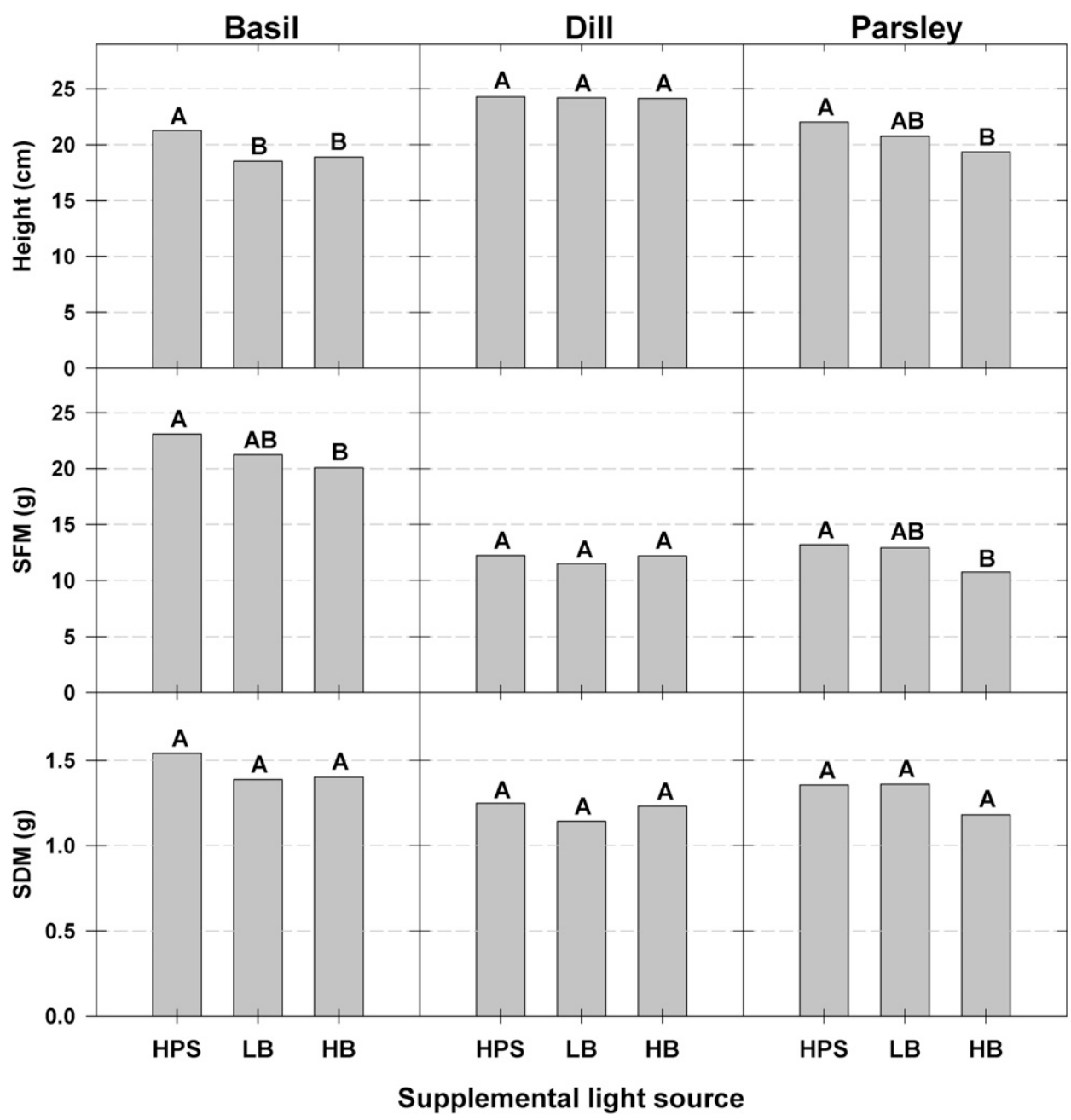

Fig. 2. Height, shoot fresh weight (SFM), and shoot dry mass (SDM) of basil, dill, and parsley grown in deep-flow technique hydroponic systems under ambient light supplemented with $100 \mu \mathrm{mol} \cdot \mathrm{m}^{-2} \cdot \mathrm{s}^{-1}$ of supplemental light from 0600 to $2200 \mathrm{HR}$ provided from high-pressure sodium (HPS) lamps or light-emitting diodes with a low blue (B) to red (R) ratio [LB (7:93 B:R)], or high B:R ratio [HB (30:70 B:R)]. Data were collected $21 \mathrm{~d}$ (basil) or $28 \mathrm{~d}$ (dill and parsley) after transplanting and initiating treatments. Each bar represents the mean of nine replications. Letters indicate significant differences across supplemental light sources within species using Tukey's honestly significant difference at $P \leq 0.05$.

Growth measurements and destructive harvests were performed $21 \mathrm{~d}$ (basil) or $28 \mathrm{~d}$ (dill and parsley) after initiating treatments. Heights of 10 plants were recorded as the length from the surface of the foam board to the apical meristem. Plants were then severed at the substrate surface and shoot fresh weight (SFM) was immediately recorded. Fresh tissue was then tripled-rinsed in deionized water after weighing and placed in a paper bag in a forced-air oven at $67^{\circ} \mathrm{C}$ for $3 \mathrm{~d}$, after which shoot dry mass (SDM) was recorded.

Three additional plants harvested from each treatment replication were used for chlorophyll content, aroma, and phenolic concentration analyses. Preparation of samples for chlorophyll analysis was done by cutting $\approx 150 \mathrm{mg}$ of leaf tissue into $1.5-\mathrm{mL}$ centrifuge tubes and flash-freezing in liquid nitrogen. Samples were then ground into a powder within their respective centrifuge tubes and $1.5-\mathrm{mL}$ aliquots of reagentgrade ethanol were added before storing at $4{ }^{\circ} \mathrm{C}$ until further analysis. Samples were spun down for $2 \mathrm{~min}$ at $5000 g_{\mathrm{n}}$ in a centrifuge (5415 C; Eppendorf, Hamburg, Germany) before transferring $750 \mu \mathrm{L}$ of supernatant into a new tube and adding an additional $750 \mu \mathrm{L}$ of ethanol. Chlorophyll content was quantified by spectrophotometer (Genesys 20 Visible Spectrophotometer; Spectronic Instruments, Rochester, NY) at 665 and $649 \lambda$ for chlorophyll a and $b$, as described by Ritchie (2006).

Aroma AND flavor analyses. About 2 to $3 \mathrm{~g}$ of fresh leaf tissue from up to three plants within each rep were placed into glass sampling jars for $30 \mathrm{~min}$, and were then analyzed for aroma compounds by a gas chromatograph (model 3700; Varian, Palo Alto, CA) with integrator (3390A Integrator; Hewlett Packard, Palo Alto, CA) using a 30m column (DB5; J\&W Scientific, Folsom, CA). Protocol followed the method by Wilson et al. (1992), set to an initial temperature of $30^{\circ} \mathrm{C}$ for 2 min, followed by single-step ramping of temperature at $7{ }^{\circ} \mathrm{C}$ per min until $200{ }^{\circ} \mathrm{C}$ was reached, then held for $5 \mathrm{~min}$. Peaks were identified using standards for predominate aroma compounds common to each species (Justesen and Knuthsen, 2001; U.S. Department of Agriculture, 2011).

Phenolic concentration of key flavor compounds was prepared by extracting analytes from plant material into a methanol solvent solution for sample preparation as described by Khoddami et al. (2013). To reduce particle size for better extraction, 1 to $2 \mathrm{~g}$ of plant material were cut from mature leaves, weighed, and inserted into a $15-\mathrm{mL}$ centrifuge tube with a milling ball $(10 \mathrm{~mm}$ PM 100 planetary mill grinding ball; Retsch Technology, Haan, Germany) and flash-frozen in liquid nitrogen. Frozen samples were then shaken and vortexed until tissue was ground into a fine powder. Aliquots of $7.5 \mathrm{~mL}$ of methanol solvent were added to each centrifuge tube and then vortexed, left at room temperature before filtration through filter paper (Whatman No. 2 filter paper; GE Healthcare UK, Little Chalfont, UK), and transferred into a $2-\mathrm{mL}$ auto sampler vial.

Samples were analyzed by quadruple time-of-flight highperformance liquid chromatography (6450 QTOF HPLC; Agilent Technologies, Santa Clara, CA) with a column (XDB $\mathrm{C} 18,4.6 \times 150 \mathrm{~mm}, 1.8 \mu$, Agilent Technologies) at a flow rate of $700 \mu \mathrm{L} \cdot \mathrm{min}^{-1}$ and temperature maintained at $30^{\circ} \mathrm{C}$. Samples were injected at a volume of $5 \mu \mathrm{L}$ with a solvent gradient of $95 \%$ solvent $\mathrm{A}\left(1: 1 \mathrm{H}_{2} \mathrm{O} / \mathrm{MeOH}\right.$ with $1 \%$ formic acid) to $5 \%$ solvent B (ACN with $0.1 \%$ formic acid) held for $5 \mathrm{~min}$; and then changing to $5 \%$ solvent A to $95 \%$ solvent B over $10 \mathrm{~min}$ and held for $3 \mathrm{~min}$. Analytes were read at an ultraviolet wavelength 


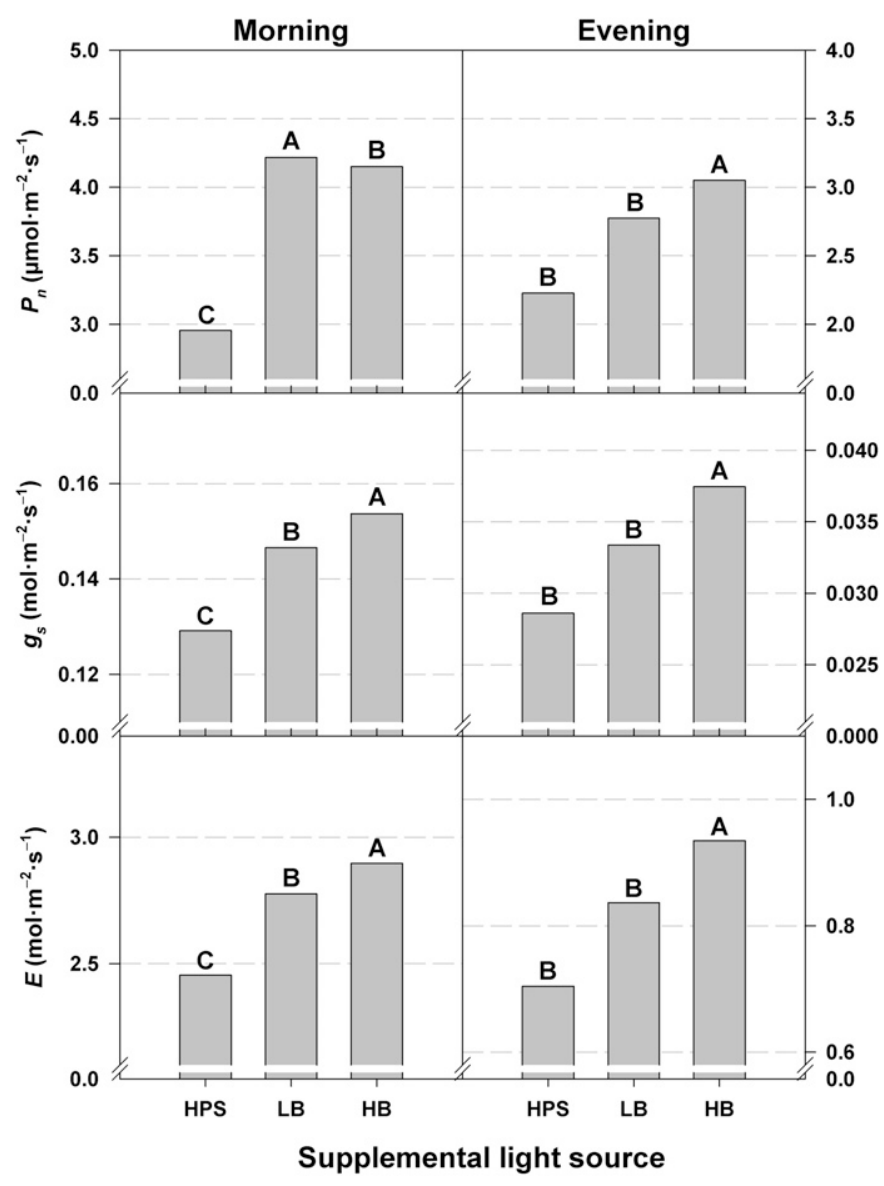

Fig. 3. Photosynthesis $\left(P_{n}\right)$, stomatal conductance $\left(g_{\mathrm{S}}\right)$, and transpiration $(E)$ for basil grown in hydroponic systems under ambient light supplemented with $100 \mu \mathrm{mol} \cdot \mathrm{m}^{-2} \cdot \mathrm{s}^{-1}$ of supplemental light from 0600 to $2200 \mathrm{HR}$ provided from high-pressure sodium (HPS) lamps or light-emitting diodes with a low blue (B) to red (R) ratio [LB (7:93 B:R)], or high $\mathrm{B}: \mathrm{R}$ ratio [HB $(30: 70 \mathrm{~B}: \mathrm{R})]$. Measurements presented were taken during the morning (0600-0800 HR) and evening (2000-2200 HR), $20 \mathrm{~d}$ after initiating treatments. Each bar represents the mean of nine replications. Letters indicate significant differences across supplemental light sources within species using Tukey's honestly significant difference at $P \leq 0.05$.

of $280 \mathrm{~nm}$ after initial confirmation of protocol and peak identification with standards for target analytes.

EXPERIMENTAL DESIGN AND STATISTICAL ANALySES. The experiment was designed as a randomized complete block design for each species. There were three replications (individual DFT systems) for each supplemental light treatment, with ten subsamples (individual plants) averaged in each replicate for growth measurements, and three subsamples averaged for physiological measurements. Replications were blocked across three runs over time. Data were analyzed using two-way ANOVA $(\alpha=0.05)$ in SigmaPlot (version 11.0; Systat Software, San Jose, CA). Tukey's honestly significant difference was used for mean separation.

\section{Results}

BASIL. The light source affected morphology, with one or both LED lighting treatments resulting in shorter plants with less SFM compared with plants grown under HPS lamps. For example, basil height, when grown under both LEDs, was 2.5

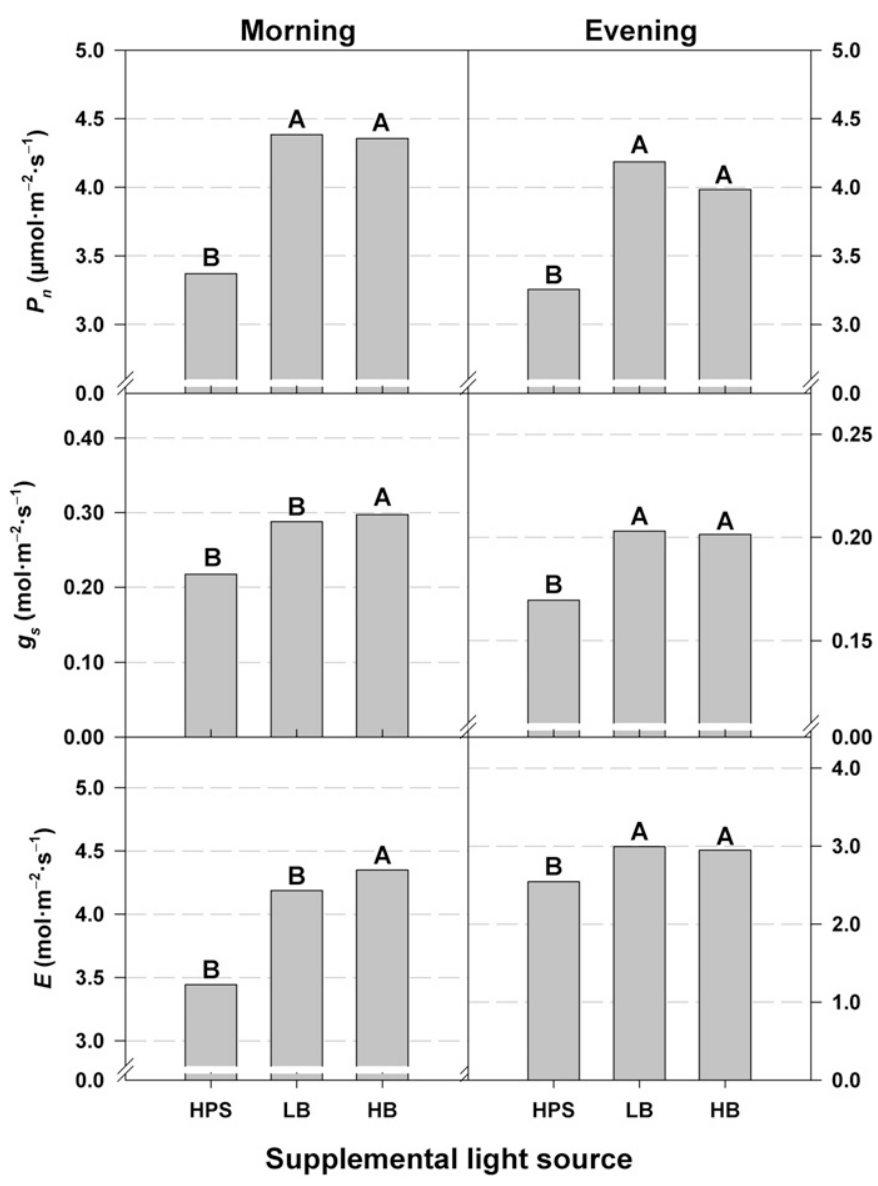

Fig. 4. Photosynthesis $\left(P_{n}\right)$, stomatal conductance $\left(g_{\mathrm{S}}\right)$, and transpiration $(E)$ for parsley grown in hydroponic systems under ambient light supplemented with $100 \mu \mathrm{mol} \cdot \mathrm{m}^{-2} \cdot \mathrm{s}^{-1}$ of supplemental light from 0600 to $2200 \mathrm{HR}$ provided from high-pressure sodium (HPS) lamps or light-emitting diodes with a low blue (B) to red $(\mathrm{R})$ ratio [LB $(7: 93 \mathrm{~B}: \mathrm{R})]$, or high $\mathrm{B}: \mathrm{R}$ ratio [HB $(30: 70 \mathrm{~B}: \mathrm{R})]$. Measurements presented were taken during the morning (0600-0800 HR) and evening (2000-2200 HR) 27 d after initiating treatments. Each bar represents the mean of nine replications. Letters indicate significant differences across supplemental light sources within species using Tukey's honestly significant difference at $P \leq 0.05$.

cm shorter compared with those under HPS lighting $(21.3 \mathrm{~cm})$. While HB-grown basil had a SFM of $20.1 \mathrm{~g}$ (3.0 g less than those under HPS), the SDM of basil was similar across all light source treatments (Fig. 2).

Over the course of the day, from morning to afternoon (data not shown) and evening, gas exchange was higher in either one or both LED-grown basil compared with HPS-grown. In the morning $P_{n}$ was $19 \%$ and $21 \%$ higher in HB- and LB-grown basil compared with HPS, respectively (Fig. 3), though by evening only HB-treated plants had higher $P_{n}$ than HPS-grown plants $(37 \%)$ - and had the least reduction in $P_{n}$ over the course of the day (9\%) compared with HPS (21\%) (Fig. 3). Similarly, $g_{\mathrm{S}}$ for basil in the evening was $31 \%$ higher for plants grown under HB compared with HPS. While $E$ was successively higher across treatments in the morning for LB- and HB-grown basil compared with HPS, only basil grown under HB had higher $E(33 \%$ increase) than those under HPS lighting in the evening.

The $F_{v} / F_{m}$ was similar for all treatments in the morning (data not shown). By the evening, $F_{v} / F_{m}$ declined slightly with LB- 


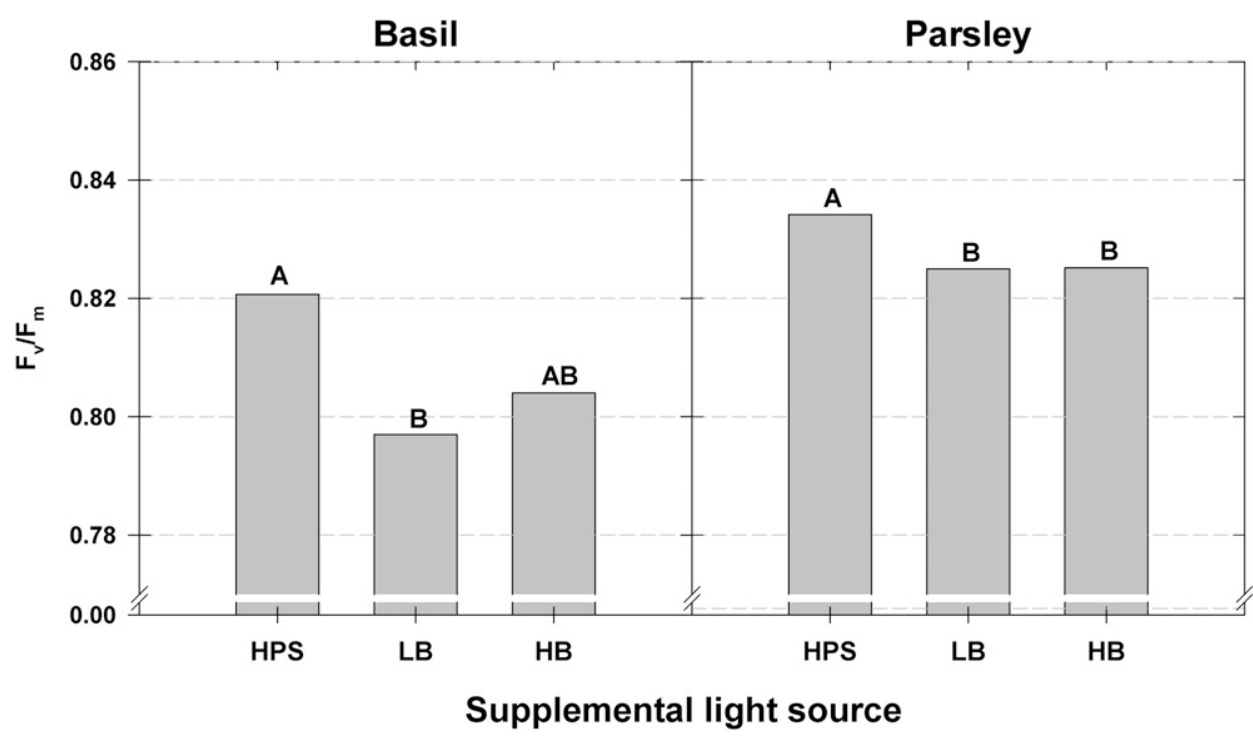

Fig. 5. Chlorophyll fluorescence $\left(F_{v} / F_{m}\right)$ at evening (2000-2200 HR) after $20 \mathrm{~d}$ for basil and $27 \mathrm{~d}$ for parsley. Plants were grown in hydroponic systems under ambient light supplemented with $100 \mu \mathrm{mol} \cdot \mathrm{m}^{-2} \cdot \mathrm{s}^{-1}$ of supplemental light from 0600 to $2200 \mathrm{HR}$ provided from high-pressure sodium (HPS) lamps or light-emitting diodes with a low blue (B) to red (R) ratio [LB (7:93 B:R)], or high B:R ratio [HB (30:70 B:R)]. Data were collected in the evening (2000-2200 HR), $20 \mathrm{~d}$ (basil) or $27 \mathrm{~d}$ (parsley) after transplanting and initiating treatments. Each bar represents the mean of nine replications. Letters indicate significant differences across supplemental light sources within species using Tukey's honestly significant difference at $P \leq 0.05$.

grown basil, having a lower $F_{v} / F_{m}(0.800)$ compared with those grown under HPS lighting [0.820 (Fig. 5)]. Although chlorophyll a had similar concentrations across lighting treatments (3.93 $\left.\mu \mathrm{g} \cdot \mathrm{mg}^{-1}\right)$, chlorophyll b of basil grown under LB $\left(3.60 \mu \mathrm{g} \cdot \mathrm{mg}^{-1}\right)$ increased by $30 \%$ and $42 \%$ compared with those grown under HB and HPS, respectively (Fig. 6).

In addition to morphology and gas exchange, secondary metabolites of essential oils and phenolics accumulation for basil were affected by supplemental light, and these tended to increase under LED lighting. For example, myrcene was $134 \%$ higher in HB-grown plants compared with HPS (Fig. 10). Similarly, both LED-grown basil had higher concentrations myricetin and orientin, but were lower in kaempferol, compared with those grown under HPS. Only HB-grown plants had higher concentrations of isorhamnetin compared with HPSgrown (Fig. 7). Myricetin exhibited a 2 -fold increase in concentration in basil grown under either LED light source, compared with HPS lighting.

Dill. Height, SFM, and SDM of dill were $24.2 \mathrm{~cm}, 12.0 \mathrm{~g}$, and $1.22 \mathrm{~g}$ respectively, and these factors were unaffected by supplemental light source (Fig. 2). Chlorophyll a concentrations were similar across treatments. However, concentrations of chlorophyll b were higher in LB-treated plants compared with either HB or HPS by $28 \%$ and $26 \%$, respectively (Fig. 6).

Essential oil accumulation in dill was more affected by LB lighting than HB lighting, and although trends for higher essential oil content were observed under LED lighting compared with HPS (Fig. 10), only LB-grown dill had 322\% more myrcene and $285 \%$ more cineole than under HPS lighting. Flavonoid concentrations were generally higher in LED-grown dill, with a trend of higher phenolic content with increasing B light content (except for kaempferol, which was $84 \%$ higher in LB-treated than HPS). Flavonoid concentrations of quercetin, myricetin, myristicin, and dillapiole were $177 \%, 98 \%, 128 \%$, and $89 \%$ higher, respectively, in dill grown under HB lighting compared with HPS lighting (Fig. 8). Notably, quercetin concentration was 2.8 times higher in plants grown under HB compared with HPS.

Parsley. Light source and quality affected parsley growth, as both LB- and HB-grown plants were shorter than HPS-grown; but only HB-grown basil and parsley had less SFM than HPS. For instance, the height of parsley under LED lights was $2.7 \mathrm{~cm}$ shorter compared with those under HPS [22.0 cm (Fig. 2)]. Similarly, the SFM of HB-grown parsley was $2.4 \mathrm{~g}$ less than HPS $(13.2 \mathrm{~g})$. The SDM of parsley was similar across lighting treatments.

Morning $P_{n}$ was higher for parsley under LB and HB LEDs compared with HPS-grown plants by $29 \%$ and $30 \%$, respectively (Fig. 4 ), and remained higher into the evening. While in the morning the $g_{\mathrm{S}}$ of parsley was $3 \%$ higher under HB light than LB, $g_{S}$ was $37 \%$ higher under HB than HPS. By evening, both HB- and LB-grown plants had $19 \%$ and $20 \%$ more $g_{\mathrm{S}}$ than HPS-grown plants, respectively. Transpiration $(E)$ was highest in HB-grown parsley in the morning with $4 \%$ and $26 \%$ higher $E$ than LB or HPS, respectively; though by evening, both LED-grown parsley had higher $E$ than plants under HPS. In contrast, $F_{v} / F_{m}$ of parsley was 0.840 across treatments in the morning (data not shown), although LB- and HB-grown plants decreased to 0.825 by evening, and these were slightly lower than HPS (0.834) (Fig. 5). Although chlorophyll a content of parsley $\left(5.77 \mu \mathrm{g} \cdot \mathrm{mg}^{-1}\right)$ was similar across lighting treatments, chlorophyll $\mathrm{b}$ in parsley was highest in LB-grown plants, $22 \%$ greater than HPS-grown plants.

Parsley grown under LEDs also had higher concentrations of essentials oils, with $343 \%$ and $248 \%$ higher myrcene accumulation compared with HPS-grown plants for LB- or HB-grown parsley, respectively (Fig. 10). Additionally, while all the concentrations of flavonoids kaempferol, quercetin, apigenin, apiole, and malyopiniin in LED-grown parsley tended to be higher than in HPS-grown plants, only isorhamnetin was significantly affected by light source, with a $90 \%$ increase in concentration for HB-grown plants compared with HPS-grown plants (Fig. 9).

\section{Discussion}

Supplemental lighting from HPS lamps is common in greenhouse crop production. However, the results of our research, with respect to plant growth, development, and quality, demonstrate the potential benefits of using supplemental narrow-spectra LED lighting for efficiently producing and increasing the quality of crops, compared with traditional broad-spectrum, high-intensity light sources. We believe many of the effects reported herein are related to the amount of B light from the different light sources. The spectral distribution of 


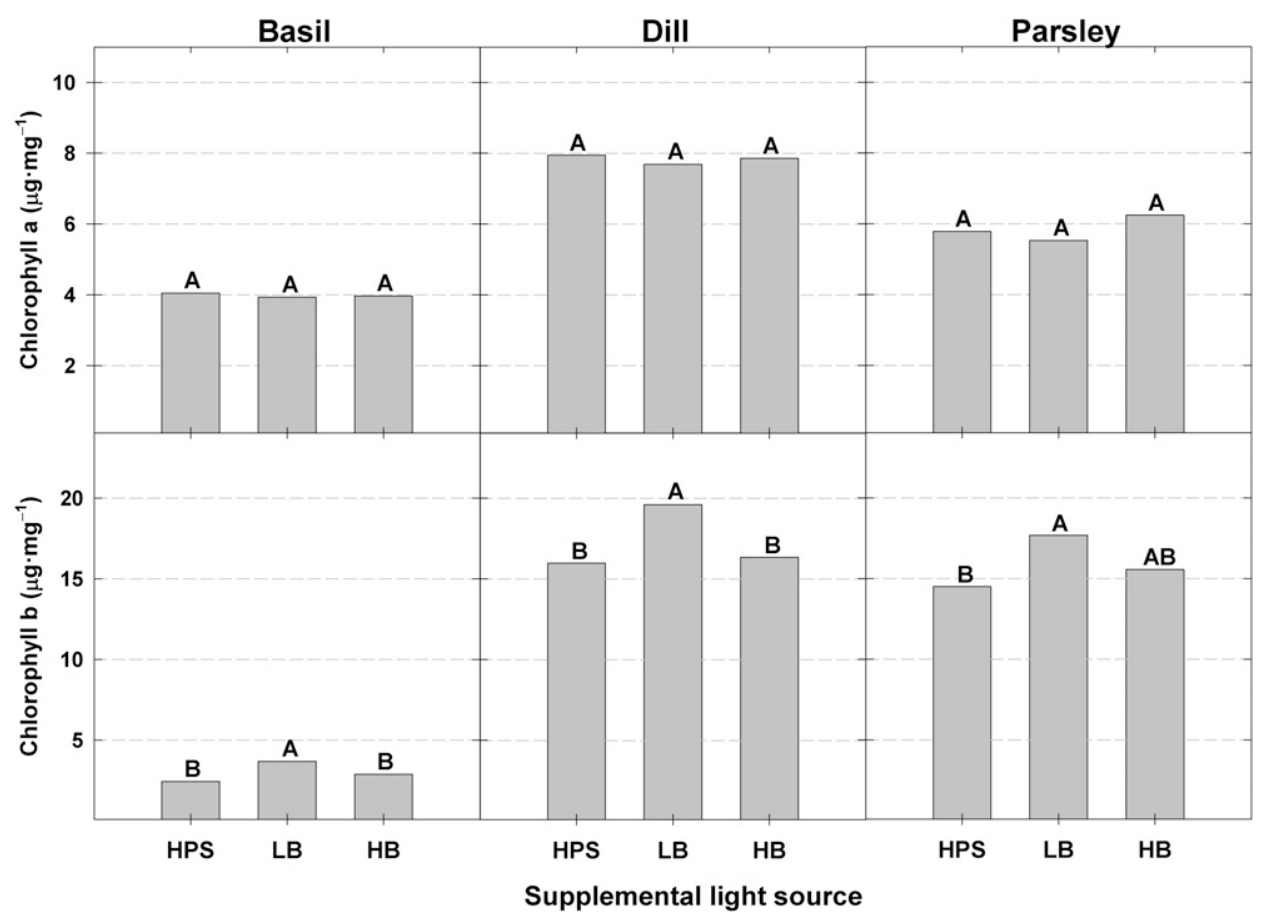

Fig. 6. Chlorophyll a and b content of basil, dill, and parsley grown in deep-flow technique hydroponic systems under ambient light supplemented with $100 \mu \mathrm{mol} \cdot \mathrm{m}^{-2} \cdot \mathrm{s}^{-1}$ of supplemental light from 0600 to $2200 \mathrm{HR}$ provided from high-pressure sodium (HPS) lamps or light-emitting diodes with a low blue (B) to red (R) ratio [LB (7:93 $\mathrm{B}: \mathrm{R})$ ], or high $\mathrm{B}: \mathrm{R}$ ratio [HB (30:70 B:R)]. Data were collected $21 \mathrm{~d}$ (basil) or $28 \mathrm{~d}$ (dill and parsley) after transplanting and initiating treatments. Each bar represents the mean of nine replications. Letters indicate significant differences across supplemental light sources within species using Tukey's honestly significant difference at $P \leq 0.05$.

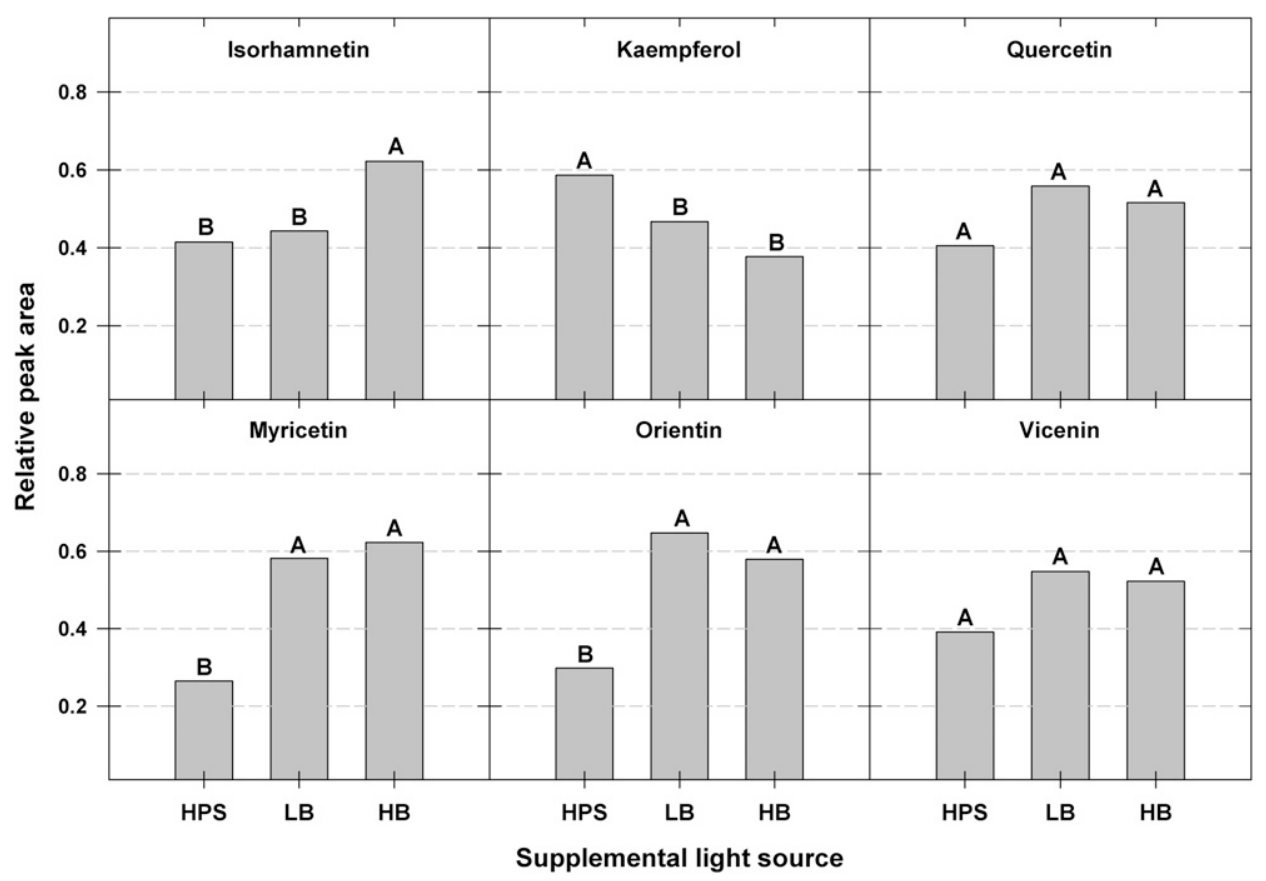

Fig. 7. Relative content of isorhamnetin, kaempferol, quercetin, myricetin, orientin, and vicenin accumulated in basil. Plants were grown in deep-flow technique hydroponic systems under ambient light supplemented with 100 $\mu \mathrm{mol} \cdot \mathrm{m}^{-2} \cdot \mathrm{s}^{-1}$ of supplemental light from 0600 to $2200 \mathrm{HR}$ provided from high-pressure sodium (HPS) lamps or light-emitting diodes with a low blue $(\mathrm{B})$ to red $(\mathrm{R})$ ratio [LB (7:93 B:R)], or high B:R ratio [HB (30:70 B:R)]. Data were collected $21 \mathrm{~d}$ after transplanting and initiating treatments, and presented as normalized relative counts to each other. Each bar represents the mean of nine replications. Letters indicate significant differences across supplemental light sources within species using Tukey's honestly significant difference at $P \leq 0.05$.
$P A R$ may be broadly characterized for color [B: $400-500 \mathrm{~nm}$; G: 500 $600 \mathrm{~nm}$; R: 600-700 nm (Cope et al., 2014)]. Based on this categorization, the proportion of $\mathrm{B}$ light in our HPS lights is $6 \%$. However, classifying the spectral distribution of our supplemental light sources by the peak wavelengths for absorption across the $P A R$ action spectrum for plants, such as with LEDs (B: $450 \pm$ $20 \mathrm{~nm}$; R: $660 \pm 20 \mathrm{~nm}$ ), which are similar to foci of $\mathrm{B}$ and $\mathrm{R}$ light bandwidth ranges reported by Chen et al. (2016) and others for spectral peaks (Inada, 1976; Kopsell et al., 2015; Randall and Lopez, 2015), the $\mathrm{B}$ light in HPS lamps is $2.7 \% \mathrm{~B}$ light. As a result, we see a doseresponse effect of supplemental B light on gas exchange, growth, morphology, and secondary metabolic functions. Although basil (LB- and HB-grown) and parsley (HBgrown) were shorter, and both species under HB had less SFM compared with plants grown under HPS light, these factors are minor with respect to implications for commercial CEA crop production. Furthermore, for many of the other parameters analyzed, such as SDM, gas exchange, and aroma and flavor compounds, plants grown under LED lighting had similar or enhanced characteristics to those grown under conventional HPS lighting.

Supplemental light source affected plant height differently among species; basil (LB and HB) and parsley (HB) were shorter than those grown under HPS lighting, while dill was unaffected by light source. Parsley plants grown under HB were also shorter than under HPS light. These results align well with other reports of plant height suppression under LED lighting compared with HPS in species not studied here. Wheeler et al. (1991) reported that soybean (Glycine max) stem length was suppressed when grown under HPS lighting when additional B light was added. Hernández and Kubota (2016) reported accumulating degrees of height suppression for cucumber grown under increasing amounts of B light. Stem elongation is associated with several mechanisms, including etiolation and shade 


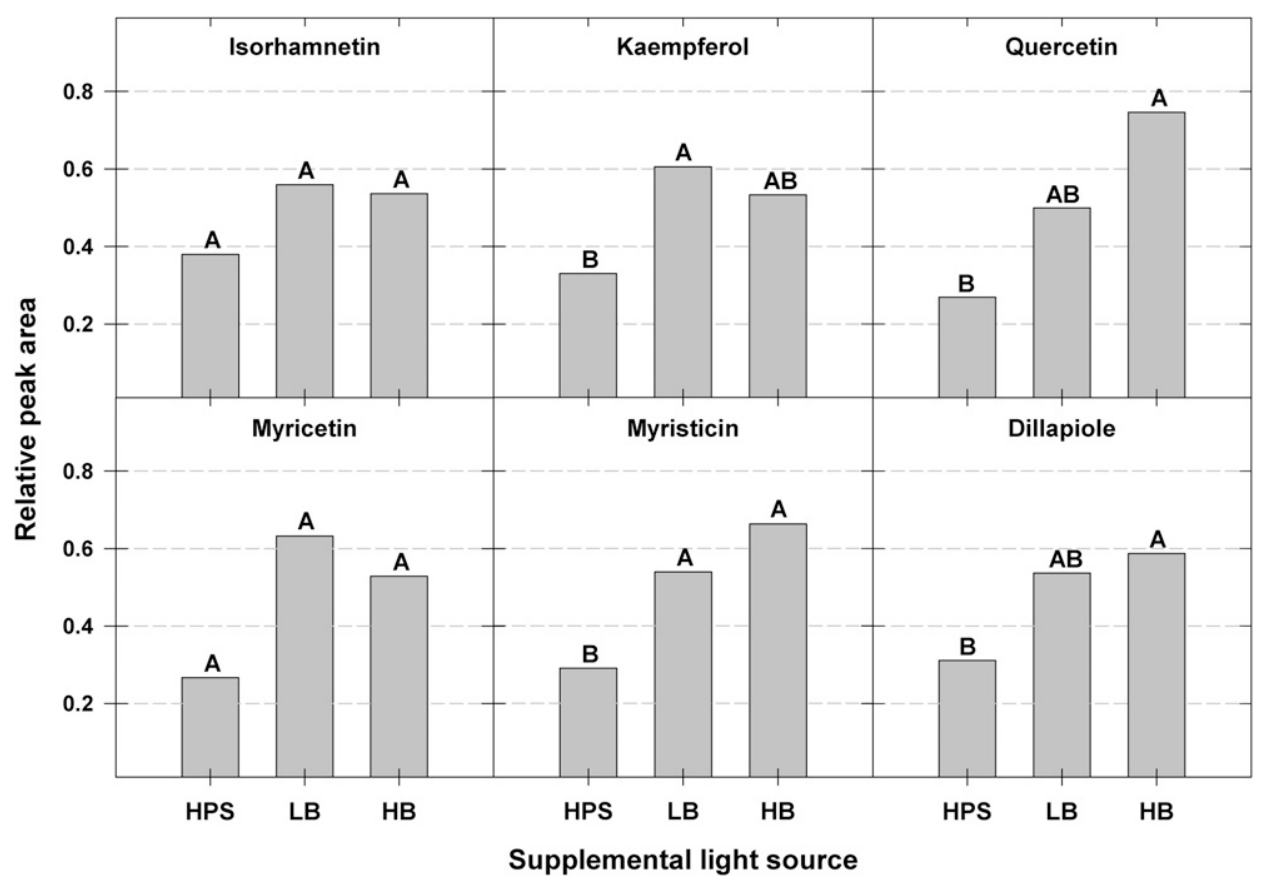

Fig. 8. Relative content of isorhamnetin, kaempferol, quercetin, myricetin, myristicin, and dillapiole accumulated in dill. Plants were grown in deep-flow technique hydroponic systems under ambient light supplemented with $100 \mu \mathrm{mol} \cdot \mathrm{m}^{-2} \cdot \mathrm{s}^{-1}$ of supplemental light from 0600 to $2200 \mathrm{HR}$ provided from high-pressure sodium (HPS) lamps or light-emitting diodes with a low blue $(\mathrm{B})$ to red $(\mathrm{R})$ ratio [LB $(7: 93 \mathrm{~B}: \mathrm{R})]$, or high B:R ratio [HB (30:70 B:R)]. Data were collected $28 \mathrm{~d}$ after transplanting and initiating treatments, and presented as normalized relative counts to each other. Each bar represents the mean of nine replications. Letters indicate significant differences across supplemental light sources within species using Tukey's honestly significant difference at $P \leq 0.05$.

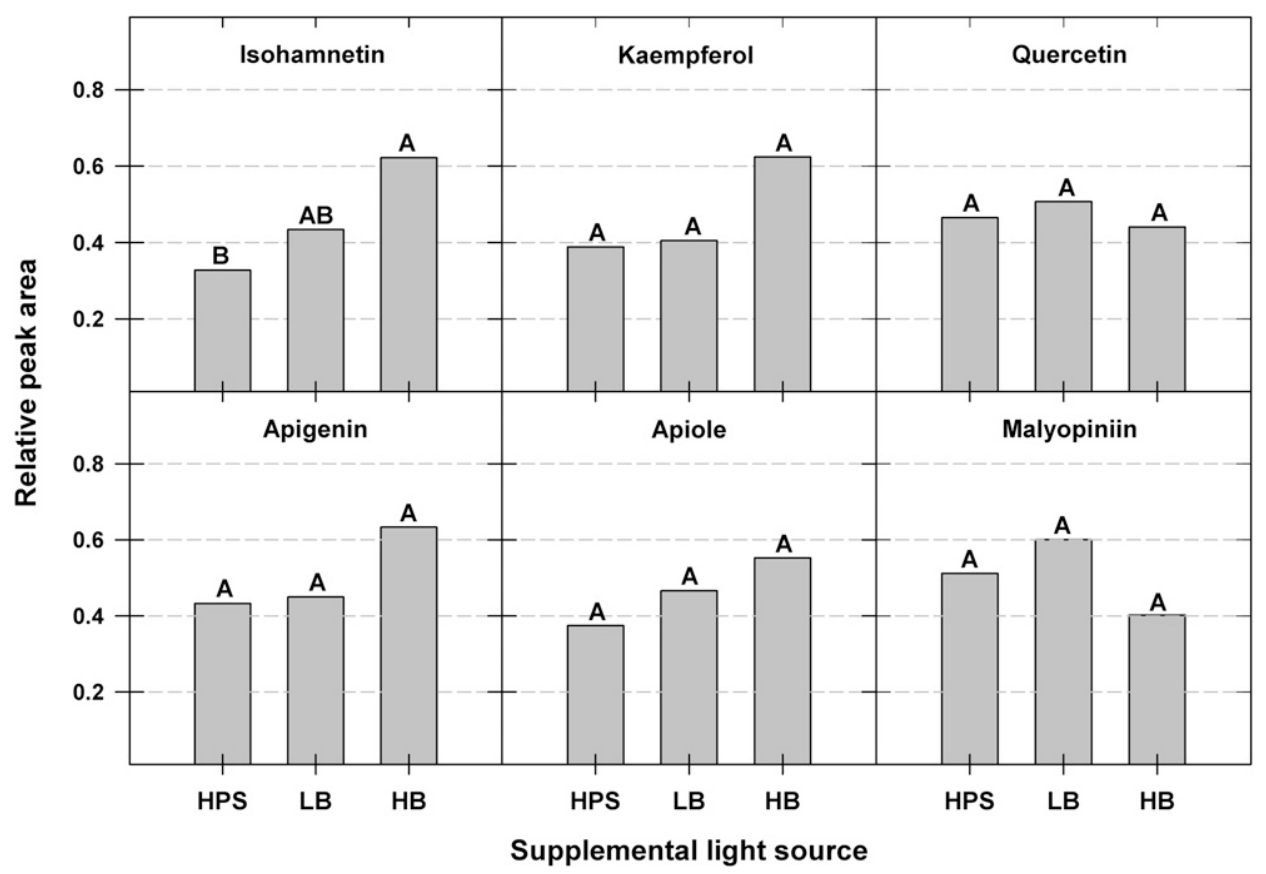

Fig. 9. Relative content of isorhamnetin, kaempferol, quercetin, apigenin, apiole, and malyopiniin accumulated in parsley. Plants were grown in deep-flow technique hydroponic systems under ambient light supplemented with $100 \mu \mathrm{mol} \cdot \mathrm{m}^{-2} \cdot \mathrm{s}^{-1}$ of supplemental light from 0600 to $2200 \mathrm{HR}$ provided from high-pressure sodium (HPS) lamps or light-emitting diodes with a low blue (B) to red (R) ratio [LB (7:93 B:R)], or high B:R ratio [HB (30:70 B:R)]. Data were collected $28 \mathrm{~d}$ after transplanting and initiating treatments, and presented as normalized relative counts to each other. Each bar represents the mean of nine replications. Letters indicate significant differences across supplemental light sources within species using Tukey's honestly significant difference at $P \leq 0.05$. avoidance. Shorter stem lengths occur when R:FR is high (Lorrain et al., 2008), like this study, in which the LED lamps do not emit FR light, but HPS lamps do. Both basil and parsley were shorter and had less SFM under one or both of the LEDs, compared with those under HPS lighting; but the number of nodes (data not shown) were similar across lighting treatments. While increased stem elongation may result in a larger plant, such an outcome does not necessarily mean increased SDM, and such a result is undesirable for some, such as with producers of containerized ornamental plants (Randall and Lopez, 2015).

As $P_{n}$ increases, generally so does $g_{\mathrm{S}}$ and $E$, and were all at least similar or greater for LED-treated basil and parsley at any time of the day compared with HPS (Figs. 3 and 4), despite less SFM under HB than HPS light. Within each species, plants had similar SDM across treatments, and the differences in SFM can be attributed to varying water content. Gas exchange can increase with B light; with basil, $P_{n}$ under HB and LB LEDs is up to $39 \%$ and $35 \%$ higher, and $g_{\mathrm{S}}$ is $21 \%$ and $14 \%$ higher over the course of the day compared with plants under HPS, respectively. With up to $95 \%$ of water uptake transported directly for gas exchange (McElrone et al., 2013), and available internal water content driving turgor pressure cell expansion (Cosgrove, 2000) for internode elongation under light (Huber et al., 2014), the increased gas exchange measured under $\mathrm{HB}$ light may have contributed to shorter height and less SFM under HB light for basil and parsley compared with HPS. Yet differences in species' responses to light sources vary (van Iersel and Gianino, 2017), as seen in this study where $g_{\mathrm{S}}$ and $E$ were greater under LB and HB LEDs than under HPS for basil than with parsley (Figs. 3 and 4). In the morning, gas exchange is influenced by B light photoreceptors such as cytochromes and phototropins, which aid $g_{\mathrm{S}}$ by playing a role in promoting guard cell opening to initiate gas exchange in the morning (Humble and Hsiao, 1970). Thus, while $P_{n}$ was generally higher in 


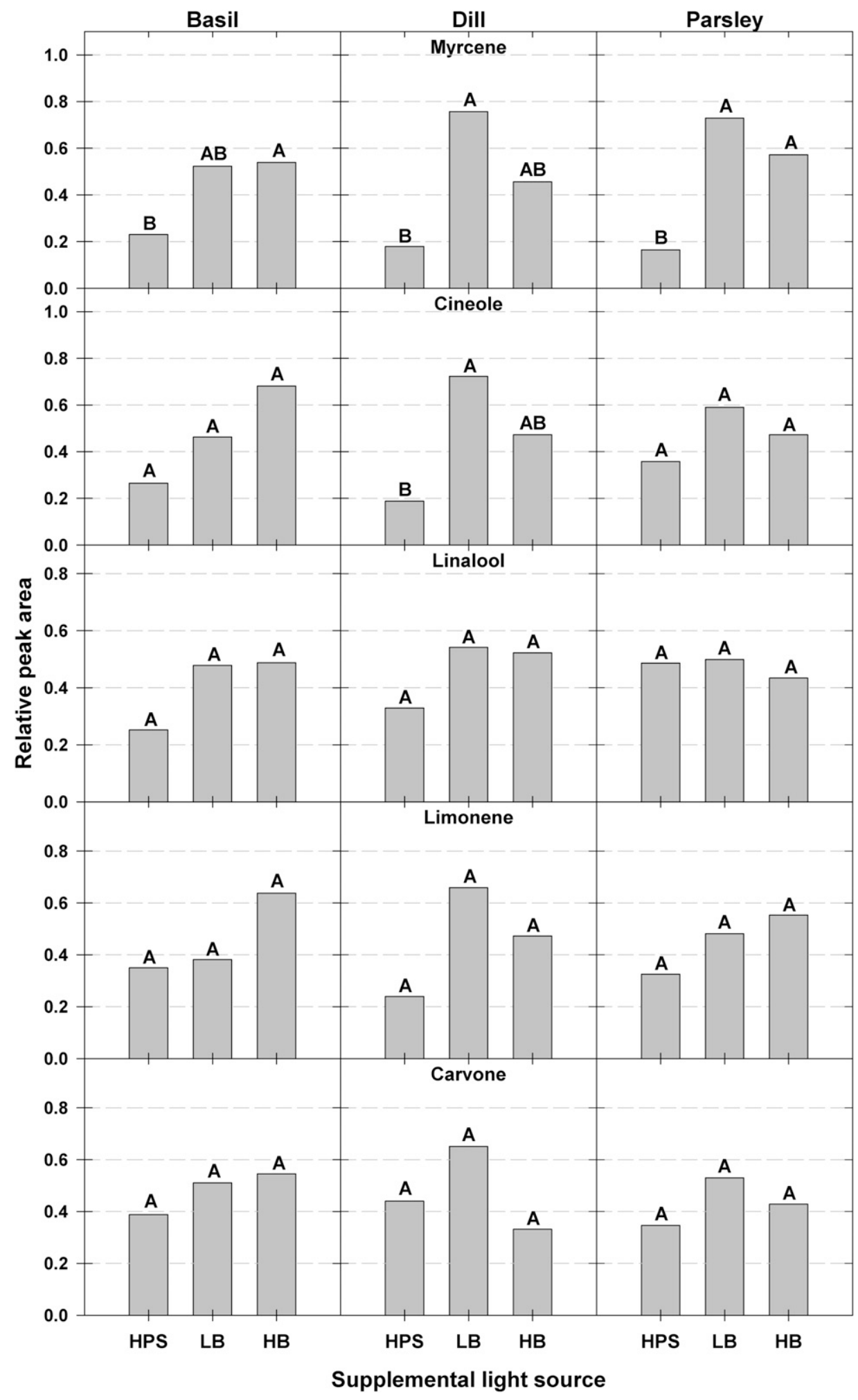

Fig. 10. Relative content of myrcene, cineole, linalool, limonene, and carvone essential oil accumulation for basil, dill, and parsley. Essential oil content was measured by headspace gas chromatography of volatized aromatics, and data are presented as normalized relative counts. Plants were grown in deep-flow technique hydroponic systems under ambient light supplemented with $100 \mu \mathrm{mol} \cdot \mathrm{m}^{-2} \cdot \mathrm{s}^{-1}$ of supplemental light from 0600 to $2200 \mathrm{HR}$ provided from high-pressure sodium (HPS) lamps or light-emitting diodes with a low blue (B) to red (R) ratio [LB (7:93 B:R)], or high B:R ratio [HB (30:70 B:R)]. Data were collected $21 \mathrm{~d}$ (basil) or $28 \mathrm{~d}$ (dill and parsley) after transplanting and initiating treatments, and presented as normalized relative counts to each other. Each bar represents the mean of nine replications. Letters indicate significant differences across supplemental light sources within species using Tukey's honestly significant difference at $P \leq 0.05$. both LED treatments compared with HPS for basil and parsley, $g_{\mathrm{S}}$ and $E$ were highest for basil in the morning under HB, followed by LB, and then HPS (Fig. 3), while parsley $g_{\mathrm{S}}$ and $E$ grown under LB was like HPS-grown plants (Fig. 4). These results are comparable with reports on B light influence on $g_{\mathrm{S}}$ (Hogewoning et al., 2010) and differences among species to B light sensitivity (Dougher and Bugbee, 1998; Reymond et al., 1992). In the evening, HB LEDs sustained higher $P_{n}, g_{\mathrm{S}}$, and $E$ and compared with basil grown under LB or HPS light. Parsley plants were less sensitive to B light, and they had generally higher gas exchange under either LED light source compared with HPSgrown plants.

As $P_{n}$ increases, or is maintained high, $F_{v} / F_{m}$ can decrease (Genty et al., 1989), especially over the course of the day (van Iersel et al., 2016). Although $F_{v} / F_{m}$ of LBgrown basil and parsley grown under both LEDs were lower than HPS by evening (Fig. 4), the effect was minimal, with plants grown under LED lamps typically having similar or greater gas exchange than under HPS. Only plants grown under HPS lighting did not experience a drop in $F_{v} / F_{m}$ from morning to evening, potentially suggesting under-use of light in HPS-grown plants. Chlorophyll content can increase inversely to $F_{v} / F_{m}$ levels under increasing $\mathrm{B}$ light (Litvin, 2019). However, although chlorophyll a remained largely unchanged across treatments (Fig. 6), chlorophyll b was higher under LB light for basil and dill compared with both HB and HPS lighting, and parsley under LB compared with under HPS. Chlorophyll b can increase to maintain gas exchange under decreasing $F_{v} / F_{m}$ (Genty et al., 1989), aligning with the results herein. However, further studies are needed to determine the effect of chlorophyll biosynthesis and catabolism. Additionally, some light-mediated stresses may increase value-added attributes of herbs.

Accentuation of aroma and flavor attributes of culinary herbs are considered desirable for consumers (Cook and Samman, 1996) and for practices increasing their accumu- 
lation, thereby adding value to fresh-cut culinary herbs. In general, accumulation of phenolic compounds varied across species in their response to light source, with basil and parsley having increased isorhamnetin under HB. However, basil had lower kaempferol under either LED light compared with HPS (Fig. 7), while there was more kaempferol for LB-grown dill compared with HPS (Fig. 8); kaempferol content of parsley was unaffected by light sources (Fig. 9). Myricetin and orientin, two major compounds found in basil, were higher under LED lighting compared with HPS, but they were similar for vicenin. Similar to the differences among species for concentration of flavor compounds in response to light quality, trends in essential oil accumulation also differed among species, with basil increasing concentrations of aroma compounds with more B light, whereas dill generally had higher concentrations when grown under LB vs. HB lighting. This variation highlights the importance of light quality for different species and the accentuation of aroma and flavor compounds.

Secondary metabolites responsible for aromatic and flavor qualities of plants are generally part of stress mitigation mechanisms designed to protect plants from abiotic and biotic stress conditions (Winkel-Shirley, 2002). Flavonoid compounds such as kaempferol, quercetin, and others are desirable phenolics for their benefits to human health (Neuhouser, 2004; Pandey and Rizvi, 2009), and they are promoted in plants via the phenylpropanoid pathway (Stahlhut et al., 2015). Although several secondary metabolites of essential oils and phenolics may aid in plant stress mitigation (Dixon and Paiva, 1995; Rehman et al., 2016; Winkel-Shirley, 2002), compounds can be explicit to specific stress signals (Dixon and Paiva, 1995; Ma et al., 2014). Likewise, the phenylpropanoid pathway can synthesize kaempferol as a final product, or conversely, synthesize quercetin, depending on the signal triggering the response (Ryan et al., 2002; Winkel-Shirley, 2002). The increase in both kaempferol and quercetin in dill under increasing B light was unexpected; however, Warren et al. (2003) reported increases of both in response to ultraviolet-B radiation, and Ryan et al. (1998) noted the quercetin:kaempferol ratio for different species may similar even if total content increased under light stress. Like basil, some major compounds found in dill increased under HB alone (dillapiole) or both LED light sources (myristicin), agreeing with reports on B light-mediated promotion of phenolics (Dixon and Paiva, 1995). Although parsley exhibited some tendencies for higher concentrations under $\mathrm{HB}$, only isorhamnetin was higher in HB-grown plants compared with HPS. Previous reports on the sensitivity of parsley to light source for promotion of flavor compounds is currently lacking, but Bugbee (2016) reported the interaction of light quality and light intensity may dictate the magnitude of plant responses. We postulate that light quality may in fact affect parsley flavonoid accumulation, but at higher light intensities than those used in the present experiment.

Accumulation of essential oils in plants can be mediated, in part, by light intensity and quality, as seen in basil (Chang et al., 2008; Fernandes et al., 2013; Hammock, 2018), by air quality (Blande et al., 2014), and natural variation across species (Rehman et al., 2016). For example, Hammock (2018) reports that at B:R LED ratios in supplemental lighting of 40:60 results in higher limonene and linalool compared with basil grown under HPS lighting. Yet, when basil was grown at B:R ratios comparable to this experiment, these concentrations are like HPS and align with our results. However, Hammock (2018) reports essential oil concentrations varied seasonally during their study, agreeing with Chang et al. (2008), a study in which basil oil content varied in response to light intensity. Compared with plants grown under HPS, myrcene was higher in LB for dill, HB for basil, or both LED treatments for parsley, while cineole was highest under LB for dill (Fig. 10). However, headspace analysis for relative essential oil content did not differ for linalool, limonene, or carvone within this study. Although there appeared to be trends of increasing essential oil accumulation in response to LEDs, and more specifically the proportion of B light fraction in LED light sources, variance in headspace data may have masked some possible treatment effects. Future studies examining B light effects on essential oil accumulation in culinary herbs are warranted.

\section{Conclusion}

Our study compared the effects of supplemental lighting from broad- and narrow-spectra light sources on growth, morphology, gas exchange, and secondary metabolite concentrations of culinary herbs. The use of narrowband LED light sources with B light fraction may slightly suppress the final height and yields compared with HPS lighting. But the potential advantages for accumulation of aroma and flavor compounds in herbs highlight the benefits for their use in commercial production. They can add value by increasing product quality through increasing compounds associated with flavor, human health, and pharmaceutical extraction. Further studies by researchers exploring the specific role of B light and culinary herbs (and the benefit to human health) would be useful to more clearly define the role of this light on culinary herb physiology.

\section{Literature Cited}

Baroli, I., G.D. Price, M.R. Badger, and S. von Caemmerer. 2008. The contribution of photosynthesis to the red light response of stomatal conductance. Plant Physiol. 146:737-747.

Beaman, A.R., R.J. Gladon, and J.A. Schrader. 2009. Sweet basil requires an irradiance of $500 \mu \mathrm{mol} \cdot \mathrm{m}^{-2} \cdot \mathrm{s}^{-1}$ for greatest edible biomass production. HortScience 44:64-67.

Blande, J.D., J.K. Holopainen, and Ü. Niinemets. 2014. Plant volatiles in polluted atmospheres: Stress responses and signal degradation. Plant Cell Environ. 37:1892-1904.

Brown, S. 1991. Culinary herb use in southern California restaurants. Calif. Agr. 45(1):4-6.

Bugbee, B. 2016. Toward an optimal spectral quality for plant growth and development: The importance of radiation capture. Acta Hort. 1134:1-12.

Chang, X., P.G. Alderson, and C.J. Wright. 2005. Effect of temperature integration on the growth and volatile oil content of basil (Ocimum basilicum L.). J. Hort. Sci. Biotechnol. 80:583-598.

Chang, X., P.G. Alderson, and C.J. Wright. 2008. Solar irradiance level alters the growth of basil (Ocimum basilicum L.) and its content of volatile oils. Environ. Expt. Bot. 63:216-223.

Chen, X., X. Xue, W. Guo, L. Wang, and X. Qiao. 2016. Growth and nutritional properties of lettuce affected by mixed irradiation of white and supplemental light provided by light-emitting diode. Scientia Hort. 200:111-118.

Cook, N.C. and S. Samman. 1996. Flavonoids - Chemistry, metabolism, cardioprotective effects, and dietary sources. Nutr. Biochem. 7:66-76.

Cope, K.R., M. Chase, and B. Bugbee. 2014. Photobiological interactions of blue light and photosynthetic photo flux: Effects of 
monochromatic and broad-spectrum light sources. Photochem. Photobiol. 90:574-584.

Cosgrove, D.J. 2000. Loosening of plant cell walls by expansins. Nature 407:321-326.

Craver, J.K., J.R. Gerovac, R.G. Lopez, and D.A. Kopsell. 2017. Light intensity and light quality from sole-source light emitting diodes impact phytochemical concentrations within Brassica microgreens. J. Amer. Soc. Hort. Sci. 142:3-12.

De Pascale, S., A. Maggio, F. Orsini, and G. Barbieri. 2006. Nutrients influence on ready to eat sweet basil quality. Acta Hort. 718:523530.

Dixon, R.A. and N.L. Paiva. 1995. Stress-induced phenylpropanoid metabolism. Amer. Soc. Plant Physiol. 7:1085-1097.

Dougher, T.A. and B.G. Bugbee. 1998. Is blue light good or bad for plants? Life Support Biosph. Sci. 5:129-136.

Fernandes, V.F., L.B. de Almeida, E.V.R. da S. Feijo, D. da C. Silva, R.A. de Oliveira, M.S. Mielke, and L.C. do B. Costa. 2013. Light intensity on growth, leaf micromorphology and essential oil production of Ocimum gratissimum. Rev. Bras. Farmacogn. 23:419-424.

Fraszczak, B., A. Golcz, R. Zawirska-Wojtasiak, and B. Janowska. 2014. Growth rate of sweet basil and lemon balm plants grown under fluorescent lamps and LED modules. Acta Sci. Pol. Hortorum Cultus $13: 3-13$

Genty, B., J.M. Briantais, and N.R. Baker. 1989. The relationship between the quantum yield of photosynthetic electron transport and quenching of chlorophyll fluorescence. Biochim. Biophys. Acta 990:87-92.

Gomez, C., R.C. Morrow, C.M. Bourget, G.D. Massa, and C.A. Mitchell. 2013. Comparison of intracanopy light-emitting diode towers and overhead high-pressure sodium lamps for supplemental lighting of greenhouse-grown tomatoes. HortTechnology 23:93-98. Hammock, H.A. 2018. The impact of blue and red LED lighting on biomass accumulation, flavor volatile production, and nutrient uptake in hydroponically grown Genovese basil. MS Thesis, Univ. Tennessee, Knoxville.

Hernández, R. and C. Kubota. 2012. Tomato seedling growth and morphological responses to supplemental led lighting red:blue ratios under varied daily solar light integrals. Acta Hort. 956:187-194.

Hernández, R. and C. Kubota. 2015. Physiological, morphological, and energy-use efficiency comparisons of LED and HPS supplemental lighting for cucumber transplant production. HortScience 50:351-357.

Hernández, R. and C. Kubota. 2016. Physiological responses of cucumber seedlings under different blue and red photon flux ratios using LEDs. Environ. Expt. Bot. 121:66-74.

Hogewoning, S.W., G. Trouwborst, H. Maljaars, W. van Ieperen, and J. Harbinson. 2010. Blue light dose-responses of leaf photosynthesis, morphology, and chemical composition of Cucumis sativus grown under different combination of red and blue light. J. Expt. Bot. 61:3107-3117.

Huang, W.Y., Y.Z. Cai, and Y. Zhang. 2009. Natural phenolic compounds from medicinal herbs and dietary plants: Potential use for cancer prevention. Nutr. Cancer 62:1-20.

Huber, H., J. De Brouwer, E. von Wettberg, H. During, and N. Anten. 2014. More cells, bigger cells or simply reorganization? Alternative mechanisms leading to changed internode architecture under contrasting stress regimes. New Phytol. 20:193-204.

Humble, G.D. and T.C. Hsiao. 1970. Light-dependent influx and efflux of potassium of guard cells during stomatal opening and closing. Plant Physiol. 46:483-487.

Inada, K. 1976. Action spectra for photosynthesis in higher plants. Plant Cell Physiol. 17:355-365.

Justesen, U. and P. Knuthsen. 2001. Composition of flavonoids in fresh herbs and calculation of flavonoid intake by use of herbs in traditional Danish dishes. Food Chem. 73:245-250.

Khoddami, A., M.A. Wilkes, and T.H. Roberts. 2013. Techniques for analysis of plant phenolic compounds. Molecules 18:2328-2375.
Kopsell, D.A., C.E. Sams, and R.C. Morrow. 2015. Blue wavelengths from LED lighting increase nutritionally important metabolites in specialty crops. HortScience 50:1285-1288.

Li, Q. and C. Kubota. 2009. Effects of supplemental light quality on growth and phytochemicals of baby leaf lettuce. Environ. Expt. Bot. 67:59-64.

Litvin, A.G. 2019. Quantifying the effects of light quantity and quality on culinary herb physiology. Ph.D. Diss., Iowa State Univ., Ames.

Lorrain, S., T. Allen, P.D. Duek, and G.C. Whitelam. 2008. Phytochrome-mediated inhibition of shade avoidance involves degradation of growth-promoting bHLH transcription factors. Plant J. $53: 312-323$

Loughrin, J.H. and M.J. Kasperbauer. 2003. Aroma content of fresh basil (Ocimum basilicum L.) leaves is affected by light reflected from colored mulches. J. Agr. Food Chem. 51:2272-2276.

Ma, D., D. Sun, C. Wang, Y. Li, and T. Guo. 2014. Expression of flavonoid biosynthesis genes and accumulation of flavonoid in wheat leaves in response to drought stress. Plant Physiol. Biochem. 80:6066.

Massa, G.D., H. Kim, R.M. Wheeler, and C.A. Mitchell. 2008. Plant productivity in response to LED lighting. HortScience 43:19511956.

McElrone, A.J., B. Choat, G.A. Gambetta, and C.R. Brodersen. 2013. Water uptake and transport in vascular plants. Nature Educ. Knowledge 4:6.

Morales, M.R. and J.E. Simon. 1996. New basil selections with compact inflorescences for the ornamental market, p. 543-546. In: J. Janick (ed.). Progress in new crops. ASHS Press, Alexandria, VA.

Neuhouser, M.L. 2004. Dietary flavonoids and cancer risk: Evidence from human population studies. Nutr. Cancer 50:1-7.

Pandey, K.B. and S.I. Rizvi. 2009. Plant polyphenols as dietary antioxidants in human health and disease. Oxid. Med. Cell. Longev. 2:270-278.

Prashar, A., I.C. Locke, and C.S. Evans. 2004. Cytotoxicity of lavender oil and its major components to human skin cells. Cell Prolif. 37:221-229.

Piovene, C., F. Orsini, S. Bosi, R. Sanoubar, V. Bregola, G. Dinelli, and G. Gianquinto. 2015. Optimal red:blue ratio in led lighting for nutraceutical indoor horticulture. Scientia Hort. 193:202-208.

Randall, W.C. and R.G. Lopez. 2015. Comparison of bedding plant seedlings grown under sole-source light-emitting diodes (LEDs) and greenhouse supplemental lighting from LEDs and high-pressure sodium lamps. HortScience 50:705-713.

Rehman, R., M.A. Hanif, Z. Mushtaq, and A.M. Al-Sadi. 2016. Biosynthesis of essential oils in aromatic plants: A review. Food Rev. Intl. 32:117-160.

Reymond, P., T.W. Short, and W.R. Briggs. 1992. Blue light activates a specific protein kinase in higher plants. Plant Physiol. 100:655661.

Ritchie, R.J. 2006. Consistent sets of spectrophotometric chlorophyll equations for acetone, methanol, and ethanol solvents. Photosynth. Res. 89:24-41.

Ryan, K.G., K.R. Markham, S.J. Bloor, J.M. Bradley, K.A. Mitchell, and B.R. Jordan. 1998. UVB radiation induced increase in quercetin:kaempferol ratio in wild-type and transgenic lines of Petunia. Photochem. Photobiol. 68:323-330.

Ryan, K.G., E.E. Swinny, K.R. Markham, and C. Winefield. 2002. Flavonoid gene expression and UV photoprotection in transgenic and mutant Petunia leaves. Phytochemistry 59:23-32.

Stahlhut, S.G. S. Siedler, S. Malla, S.J. Harrison, J. Maury, A.R. Neves, and J. Forster. 2015. Assembly of a novel biosynthetic pathway for production of the plant flavonoid fisetin in Escherichia coli. Metab. Eng. 31:84-93.

Taulavuori, K., V. Hyoky, J. Oksanen, E. Taulavuori, and R. JulkunenTiitto. 2016. Species-specific differences in synthesis of flavonoids and phenolic acids under increasing periods of enhanced blue light. Environ. Expt. Bot. 121:145-150. 
Trouwborst, G., J. Oosterkamp, S.W. Hogewoning, J. Harbinson, and W. van Ieperen. 2010. The responses of light interception, photosynthesis and fruit yield of cucumber to LED-lighting within canopy. Physiol. Plant. 138:289-300.

U.S. Department of Agriculture. 2011. USDA database for the flavonoid content of selected foods. Release 3. 6 Apr. 2019. $<$ https://www.ars.usda.gov/ARSUserFiles/80400525/Data/Flav/ Flav_R03-1.pdf/>.

van Iersel, M.W. and G. Gianino. 2017. An adaptive control approach for light-emitting diode lights can reduce the energy costs of supplemental lighting in greenhouses. HortScience 52:72-77.

van Iersel, M.W., G. Weaver, M.T. Martin, R.S. Ferrarezi, E. Mattos, and M. Haidekker. 2016. A chlorophyll fluorescence-based biofeedback system to control photosynthetic lighting in controlled environment agriculture. J. Amer. Soc. Hort. Sci. 141:169-176.

Walters, K.J. and C.J. Currey. 2015. Hydroponic greenhouse basil production: Comparing systems and cultivars. HortTechnology 25:645-650.
Warren, J.M., J.H. Bassman, J.K. Fellman, D.S. Mattinson, and S. Eigenbrode. 2003. Ultraviolet-B radiation alters phenolic salicylate and flavonoid composition of Populus trichocarpa leaves. Tree Physiol. 23:527-535.

Wheeler, R.M., C.L. Mackowiak, and J.C. Sager. 1991. Soybean stem growth under high-pressure sodium with supplemental blue lighting. Agron. J. 83:903-906.

Wilson, L.A., N.P. Senechai, and M.P. Widrlechner. 1992. Headspace analysis of the volatile oils of Agastache. J. Agr. Food Chem. 40:1362-1366.

Winkel-Shirley, B. 2002. Biosynthesis of flavonoids and effects of stress. Curr. Opin. Plant Biol. 5:218-223.

Wu, M.C., C.Y. Hou, C.M. Jiang, Y.T. Wang, C.Y. Wang, H.H. Chen, and H.M. Chang. 2007. A novel approach of LED light radiation improves the antioxidant activity of pea seedlings. Food Chem. 101:1753-1758. 